\title{
Research on Eliminating the Influence of Cloud Shadow of TM Image
}

\author{
Chen Lin, Zhou Yifu \\ Yellow River Conservancy Technical Institute \\ Kaifeng, China \\ e-mail:c17188@163.com
}

\author{
Ma Haolu \\ Yellow River Committee Information Center \\ Zhengzhou, China \\ e-mail:mahl2006@163.com
}

\begin{abstract}
The paper introduced a method eliminating the influence of cloud shadow in TM image by using the bands ratio and linear transformation. The result shows the method is very effective, especially on enhancing the image contrast and improving the detail information in the shadow.
\end{abstract}

Keywords- Remote sensing; Image enhancement; Processing by bands ratio; Eliminating the influence of shadow

\section{INTRODUCTION}

When satellite remote sensing image has the influence of cloud shadow, the reflection of corresponding objects will decrease due to the solar radiation's reduction in the shadow region. These regions are called "submerge area" which isn't usually satisfying in the practical application. The paper puts forward a method eliminating the influence of cloud shadow by using the bands ratio and linear transformation.

\section{THE TM INFORMATION IN THE STUDY AREA}

TM image was used in the study, whose spatial resolution is $30 \mathrm{~m}$. Bareness and vegetation land distribute in the study area which is mostly affected by the cloud shadow. The original image has 256 gray levels, that is to say, the image gray is between 0 and 255 . The figure 1-6 shows the six bands of the original image and the figure 7-12 shows the corresponding band's histograms. The table 1 shows the corresponding band's statistical values. The sixth band is not considered because of its particularity.

From these figures and table, we can see that the pixels with low value are dominant, the distribution range of pixels value is narrow, the means and standard deviation is low, the image is dark, the image contrast is lack and the detail is not obvious.

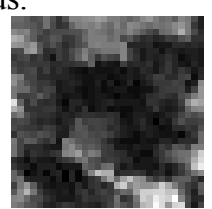

Figure $1 \mathrm{TM} 1$

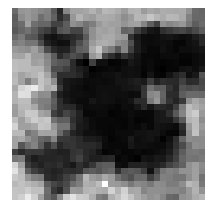

Figure 4 TM4

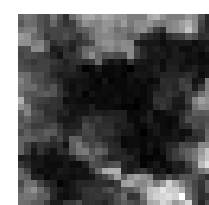

Figure 2 TM2

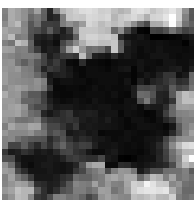

Figure 5 TM5

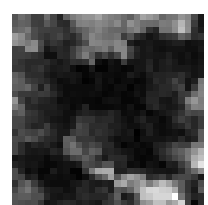

Figure 3 TM3

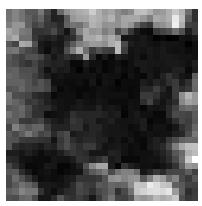

Figure 6 TM7
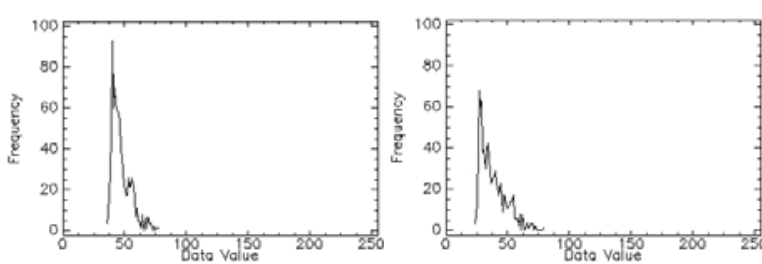

Figure 7 The histogram of TM1

Figure 8 The histogram of TM2
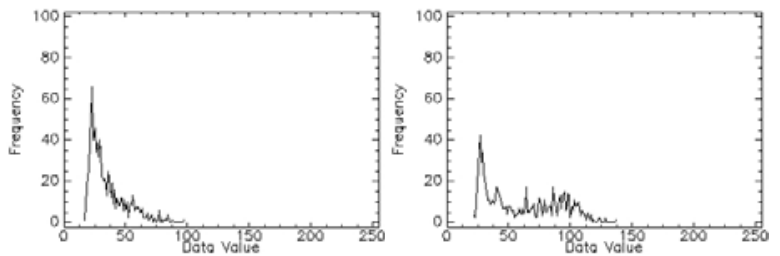

Figure 9 The histogram of TM3

Figure 10 The histogram of TM4
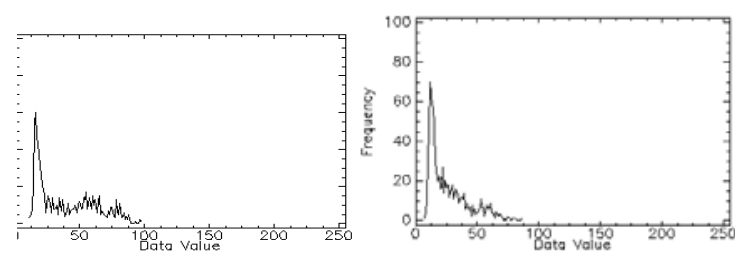

Figure 11 The histogram of TM5 Figure12 The histogram of TM7

TABLE I. STATISTICAL RESULT OF THE ORIGINAL IMAGE

\begin{tabular}{|l|l|l|l|l|}
\hline Bands & Minimum & Maximum & Mean & $\begin{array}{l}\text { Std. } \\
\text { Dev }\end{array}$ \\
\hline TM1 & 36 & 77 & 46.84 & 7.43 \\
\hline TM2 & 24 & 79 & 37.71 & 10.38 \\
\hline TM3 & 17 & 97 & 34.62 & 14.35 \\
\hline TM4 & 22 & 137 & 60.62 & 29.38 \\
\hline TM5 & 11 & 97 & 39.11 & 22.31 \\
\hline TM7 & 7 & 86 & 26.53 & 16.29 \\
\hline
\end{tabular}




\section{THE METHOD OF ELIMINATING THE INFLUENCE OF CLOUD SHADOW}

\section{A. The theory of ratio method}

The result of terrain and cloud is usually that pixel value equals the product of reflectivity and change factor, that means that every band's change factor of the same objects is equal. So the ratio method can eliminate the influence of cloud shadow ${ }^{[1]}$. The formula 1 the expression of the ratio method.

$$
f_{m / n}^{\prime}(i, j)=\frac{f_{m}(i . j)}{f_{n}(i . j)}=\frac{\alpha \rho_{m}}{\alpha \rho_{n}}=\frac{\rho_{m}}{\rho_{n}}
$$

Where $m, n$ is separately the band $m, n ; f_{m}(i, j)$ is the pixel gray value of band $m$ in row $i$ and column $j, f_{n}(i, j)$ is the pixel gray value of band $m$ in row $i$ and column $j ; \alpha$ is the change factor because of the shadow; $\rho \mathrm{m}$, $\rho n$ is separately the reflectivity of band $m, n ; f^{\prime}{ }_{m / n}(i, j)$ is the ratio of the pixel gray value of band $m$ and band $n$.

\section{B. The theory of linear transformation}

The pixel gray value will decrease and the distribution range of pixels value will be more narrow after ratio processing. The image enhancement is essential in order to increase the contrast. The paper used linear enhancement.

Assuming the pixel value $f(i, j)$ of original image is between dmin and dmax, and the pixel value $\mathrm{f}^{\prime}(\mathrm{i}, \mathrm{j})$ of the image after linear transformation is between $\mathrm{d}_{\text {min }}$ and $\mathrm{d}^{\prime}{ }_{\text {max }}$. The linear transformation can be expressed by linear function (formula 2).

$$
f^{\prime}(i, j)=\frac{\left(d_{\text {max }}^{\prime}-d_{\text {min }}^{\prime}\right)}{\left(d_{\max }-d_{\min }\right)}\left(f(i, j)-d_{\text {min }}\right)+d_{\text {min }}^{\prime}
$$

Where $f(i, j)$ is the original image pixel value in row $i$ and column $\mathrm{j} ; \mathrm{f}^{\prime}(\mathrm{i}, \mathrm{j})$ is the transformed image pixel value in row $\mathrm{i}$ and column $\mathrm{j}$.

If the transformed image has 256 gray levels, $\mathrm{d}_{\text {min }}=0$, $\mathrm{d}^{\prime}{ }_{\max }=255$, and the formula above can be expressed:

$$
f^{\prime}(i, j)=255 * \frac{\left(f(i, j)-d_{\min }\right)}{\left(d_{\max }-d_{\min }\right)}
$$

\section{Ratio processing}

The figure 13 shows the spectrum curve of the vegetation, bareness land and shadow vegetation in the study area. From the figure, we can know that the spectrum curve of the vegetation and shadow vegetation have similarity, so ratio method can eliminate the influence of shadow in a certain extent, especially, the ratio method between some bands (eg. Band 2 and band3 or band4 and band5) can obviously enhance the spectrum contrast between different objects. The paper select band 4 and band5 in processing.

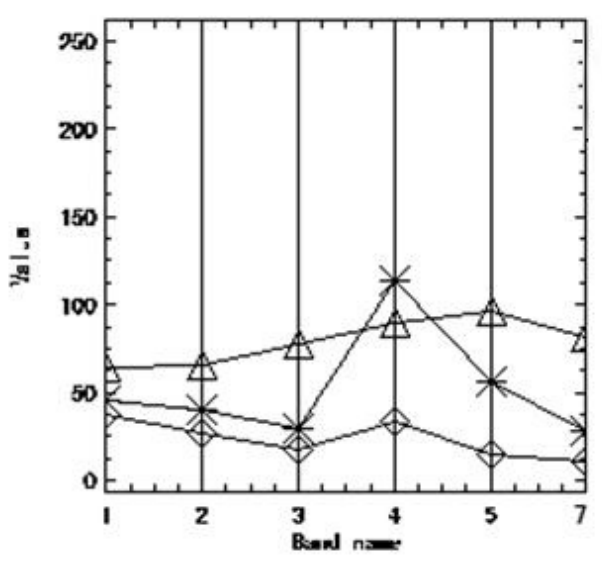

Figure 13 The spectrum curve of the vegetation, bareness land and shadow vegetation

After ratio operation of band 4 and band5, the minimum is 0.34 and the maximum is 1.25 according to formula 1 . Linear transformation can be done by applying the ratio result to formula 3 , while the transformed image is set for unsigned 8-bit. The figure 14 and 15 show the linear transformed image and its histogram. Table 2 shows the statistical result of the transformed image.

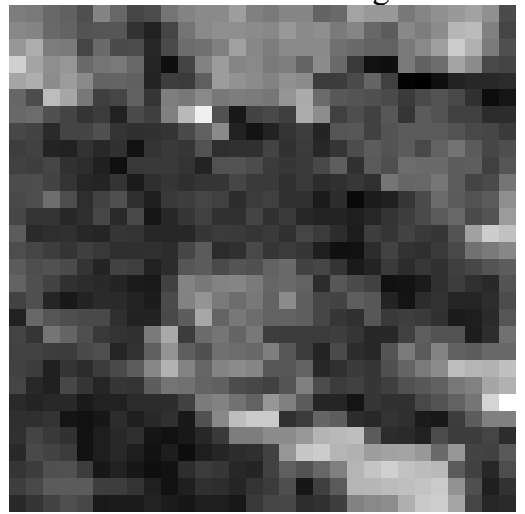

Figure14 The image after TM5/TM4 and linear transformation

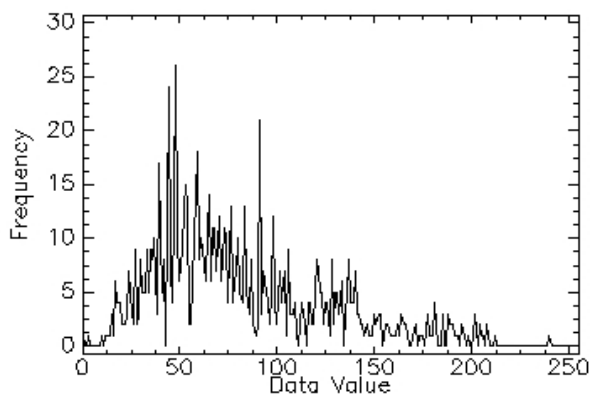

Figure 15 Histogram of transformed image

Comparing with original image, the distribution range of the image pixels value, mean and standard deviation became bigger, and image brightness was enhanced and the image 
detail is more obvious after ratio processing and linear transformation.

Table 3 shows the result comparing two same type of objects' pixel value in shadow region and non-shadow region. We can see that the same band pixel values in the original image have a bigger difference, and the difference become smaller after ratio processing and linear transformation, that proves the method has eliminated the influence of shadow in a certain extent.

Table 4 shows the result comparing two different type of objects' pixel value in non-shadow region. We can see that pixel value contrast enhanced after ratio processing and linear transformation, that proves ratio processing can enhanced different objects' contrast for selected bands according to need.

TABLE II. THE STATISTICAL RESULT AFTER RATIO PROCESSING AND LINEAR TRANSFORMATION

\begin{tabular}{|l|l|l|l|l|}
\hline \multicolumn{1}{|c|}{ Image } & Minimum & Maximum & Mean & $\begin{array}{c}\text { Std. } \\
\text { Dev }\end{array}$ \\
\hline Band5/band4 & 0.34 & 1.25 & 0.64 & 0.16 \\
\hline $\begin{array}{l}\text { Linear } \\
\text { transformation }\end{array}$ & 0 & 255 & 81.46 & 44.23 \\
\hline
\end{tabular}

TABLE III. THE RESULT COMPARING TWO SAME TYPE OF OBJECTS' PIXEL VALUE

\begin{tabular}{|l|l|l|l|l|}
\hline $\begin{array}{c}\text { Solar } \\
\text { information }\end{array}$ & TM4 & TM5 & $\begin{array}{c}\text { TM5/TM } \\
\mathbf{4}\end{array}$ & Linear trans \\
\hline $\begin{array}{l}\text { Vegetation in non- } \\
\text { shadow }\end{array}$ & 123 & 65 & 0.53 & 52 \\
\hline $\begin{array}{l}\text { Vegetation in } \\
\text { shadow }\end{array}$ & 28 & 15 & 0.54 & 54 \\
\hline
\end{tabular}

TABLE IV. THE RESULT COMPARING TWO DIFFERENT TYPE OF OBJECTS' PIXEL VALUE

\begin{tabular}{|l|l|l|l|l|}
\hline \multicolumn{1}{|c|}{ Objects } & \multicolumn{1}{|c|}{ TM4 } & \multicolumn{1}{|c|}{ TM5 } & TM5/TM4 & Linear trans \\
\hline Vegetation & 123 & 65 & 0.53 & 52 \\
\hline Bareness land & 86 & 88 & 1.02 & 192 \\
\hline
\end{tabular}

In practical application, ratio processing in selected bands according to shadow area can eliminate the influence of shadow, and extract the original image information.

\section{CONCLUSION}

The study proves that ratio processing can eliminate the influence of cloud shadow in a certain extent and extract the original information, and increase the mass of information, and enhance the image quality.

The ratio processing can enhance the contrast among soil and vegetation and so on.

The ratio processing and linear transformation can restrain the influence of shadow and enhance the objects' contrast. It is a preprocessing method in auto-classification. This method is also applicable for other image data.

\section{REFERENCES}

[1] Sun jia-bing Etc. Principle、Methods and Application of Remote Sense. Peking: Survey \& Mapping Press .1997.P259

[2] Zhao zhong-ming ,Zhu chong-guang . An Method for Removal of Thin Cloud in Remote Sensing Images[J],Remote Sensing for Environment,1996,11(3):195-199

[3] Zhang xiao-can,Hang zhi-cai ,Zhao yuan-hong. The Handling of Remote Sensing Digital Images.Hangzhou: Zhejiang University Press, 1997

[4] Xie hua-mei,Hecqi-ao,Zheng ning Etc. An Improved Method for Rapid Removal of Homomorphism Thin Cloud Remote Sensing Images Base on ERDAS Secondary Development. Journal of Peking Normal University(Natural Science), 2005,41(2):150-153.

[5] Feng Chun, Ma Jian-wen Etc., An Improved Method for Rapid Removal of Thin Cloud in Remote Sensing Images[J],Remote Sensing for Land \& Resources,2004,62:1 5.

[6] Wang hui,Tan bing Etc. An Method for Cloud in Multi-source Remote Sensing Images[J]. Journal of Survey \& Mapping Institute, 2001,18(3):195 198

[7] Huang yong-jie, Wang shuguo. Research on Removing Cloud to the Remote Sensing Images[J].Chinese Journal of Scientific Instrument,2003,24(4):490 491. .

[8] Li yue-chen, ,CHENJin Etc. An effective approach to remove cloudfogcoverand enhance remote sensing imagery[J].Journal of Chengdu University of Technolgy(Natural Science),2006,33 (11) :58 63.

[9] Zhao ying-shi Etc. Principles and Methods in Remote Sensing Application Analysis[M]. Peking: Science Press,2003.

[10] Yi ke-chu,Wang wen-tao. An approach to remove cloud Interference in Remote Sensing Images[J]. Journal of Electronic Science, 1983,5(5):271 279 . 